\title{
Validation of a radiation model for estimation of longwave net radiation at the surface
}

\author{
L. Gonima \\ C.E.F.E.-C.N.R.S., Route de Mende, B.P. 5051, F-34033 Montpellier Cedex, France
}

\begin{abstract}
Longwave radiation calculations were perfomed for the south of France. The model proposed by Gonima (1988b; Z. Meteorol. 38: 136-144), based on integration of the radiative transfer equation, was used to calculate the longwave net radiation at the surface under all sky conditions. Good agreement was obtained between measured and computed values using appropriate radiosounding data for the atmospheric profiles. Furthermore, some simple empirical expressions are proposed for the calculation of the temperature, water vapor density and pressure profiles, in order to simplify calculations of the longwave net radiation at the surface. Finally, special consideration has been given to the problem of describing temperature inversions in the atmosphere.
\end{abstract}

\section{INTRODUCTION}

The precise estimation of the longwave net radiation at the earth's surface, $L \cdots$, defined as the difference between the black-body emission of the surface, $L \uparrow$, and the incident atmospheric radiation, $L \downarrow$, represents one of the most important parts of an adequate description of the radiative heat exchange between the surface and the atmosphere. There are several means of representing longwave net radiation at the surface. From the observational data, many empirical equations have been proposed. For example, Angström (1929) and Brunt (1932) related the effective emittance of the atmosphere to the partial pressure of water vapor. Swinbank (1963) proposed 2 equations relating air temperature and the measured sky radiation, whilst Idso (1974) and Brutsaert (1975) proposed new versions of relationships based on earlier works. Recently, Choisnel (1988) used an equation of Brunt's type, adjusted for the south of France, to calculate local evapotranspiration.
Unfortunately, these empirical expressions do not always achieve reasonable agreement with experimental results, especially for short periods of time (hours or days). A detailed discussion of the limitations of empirical relationships for calculating hourly and daily values of longwave net radiation was presented in a previous work (Gonima 1988a). The present work is devoted to an experimental assessment and to verifying the importance of the contribution of the atmospheric layers above the surface for a more accurate estimate of hourly values of longwave net radiation at the surface.

\section{MODEL DESCRIPTION}

The following equation (Gonima 1988b), based on the integration of the radiative transfer equation and on the assumption that the cloud base acts as a blackbody radiator, is used to compute hourly values of the longwave net radiation at the earth's surface under all sky conditions. 


$$
\begin{aligned}
L_{c} \cdot & =(1-N) \sum_{\lambda}\left[S_{\lambda}(T(H)) P_{\lambda}\left(\tilde{k}_{\Delta \lambda} m(H)\right)\right. \\
& \left.-\frac{h c}{\mathrm{k} \lambda} \int_{0}^{H} \frac{S_{\lambda}\left(T\left(z^{\prime}\right)\right)}{T^{2}\left(z^{\prime}\right)} \gamma\left(z^{\prime}\right) P_{\lambda}\left(\tilde{k}_{\perp \lambda} m\left(z^{\prime}\right)\right) \mathrm{d} z^{\prime}\right] \\
& -N \sum_{\lambda} \frac{h c}{\mathrm{k} \lambda} \int_{0}^{h_{0}} \frac{S_{\lambda}\left(T\left(z^{\prime}\right)\right)}{T^{2}\left(z^{\prime}\right)} \gamma\left(z^{\prime}\right) P_{\lambda}\left(\tilde{k}_{\perp \lambda} m\left(z^{\prime}\right)\right) \mathrm{d} z^{\prime}
\end{aligned}
$$

where

$$
\begin{aligned}
L_{c}{ }^{\prime}= & \text { calculated longwave net radiation; } \\
N= & \text { fractional cloud cover index; } \\
\lambda= & \text { wavelength; } \\
S_{\lambda}= & \text { black-body spectral radiation of each atmos- } \\
& \text { pheric layer } ; \\
T= & \text { temperature of each atmospheric layer. The } \\
& \text { surface temperature } T\left(z^{\prime}=0\right) \text { is assumed to be } \\
& \text { equal to the air temperature, } T_{a} ; \\
H= & \text { height of the atmosphere (up to tropopause); } \\
p_{\lambda}= & \text { spectral transmission function equal to } \\
& 2 E_{3}\left(\tilde{k}_{\Delta \lambda} m\left(z^{\prime}\right)\right)_{i} \\
\tilde{k}_{\Delta \lambda}= & \text { mean absorption coefficient over a } \Delta \lambda \text {-interval; } \\
m= & \text { effective absorbing mass; } \\
h= & \text { Planck constant, equal to } 6.626176 \times 10^{-34} \mathrm{Js} ; \\
c= & \text { speed of light in vacuo } i \\
\mathrm{k}= & \text { Boltzmann constant, equal to } 1.380662 \times 10^{-23} \\
& \text { J K }{ }^{-1} ; \\
z^{\prime}= & \text { height of each atmospheric layer; } \\
\gamma= & \text { temperature gradient; and } \\
h_{0}= & \text { height of cloud base. }
\end{aligned}
$$

The exponential integral function $E_{3}$ used for the calculation of the atmospheric transmission has the following form:

$$
E_{3}(x)=\int_{1}^{\infty} e^{-x t} t^{-3} \mathrm{~d} t
$$

where $x=\tilde{k}_{\lambda_{\lambda}} m\left(z^{\prime}\right)$ and $t$ is the integration variable.

Eq. (1) includes a band model to describe atmospheric absorption. The spectral range from 5 to $100 \mu \mathrm{m}$ is used to calculate the mean absorption coefficients $\tilde{k}_{\Delta_{\lambda}}$ over a $\Delta \lambda$-interval for the mainly atmospheric absorbers: water vapor, carbon dioxide and ozone (Appendix 1).

For the calculation of the transmission function $P_{\lambda}\left(\tilde{k}_{\Delta \lambda} m\left(z^{\prime}\right)\right)$ the effective absorbing mass $m\left(z^{\prime}\right)$ for each of the aforementioned gases in each atmospheric layer $z$ needs to be specified:

$$
m\left(z^{\prime}\right)=\int_{0}^{z^{\prime}} \rho(\eta)\left[p(\eta) / p_{0}\right]^{\prime} \mathrm{d} \eta
$$

where $\rho(\eta)=$ gas density of each atmospheric absorber for an atmospheric layer $\eta_{i} p(\eta)=$ the atmospheric pressure of each layer; and the atmospheric pressure at the surface, $p_{0}$. The exponent $l$ is an unknown to be determined from experiments. Values of $l=0.9$ for water vapor, $l=0.75$ for carbon dioxide and $l=0.4$ for ozone are recommended by McClatchey et al. (1972).

\section{PROCEDURE}

Since the calculation of the longwave net radiation through Eq. (1) requires the use of aerological data, the 12:00 $\mathrm{h}$ UTC radiosounding measurements [atmospheric temperature $T\left(z^{\prime}\right)$, relative humidity $R H\left(z^{\prime}\right)$, pressure $p\left(z^{\prime}\right)$ and the corresponding height of each atmospheric layer $z^{\prime}$ ] of the Station de Radiosondage de Nîmes-Courbessac (France), situated at an altitude of $59.5 \mathrm{~m}$ at $43^{\circ} 52^{\prime} \mathrm{N}, 04^{\circ} 24^{\prime} \mathrm{E}$, were selected for the calculation of the $L_{C}{ }^{\prime}$ values

For this purpose, the integrals $\int_{0}^{H}[\ldots.] \mathrm{d} z^{\prime}$ and $\int_{0}^{z^{\prime}}[\ldots] \mathrm{d} z^{\prime}$ of Eq. (1) are evaluated by subdividing the troposphere (from $z^{\prime}=0$ to $z^{\prime}=H$ ) into $n$ horizontal layers of unequal thickness (the temperature and the atmospheric composition are assumed uniform within each layer) according to the scheme shown in Fig. 1 with

$$
\begin{aligned}
& z_{j}^{\prime u}=z_{j}^{\prime}+\left(z_{j+1}^{\prime}-z_{j}^{\prime}\right) / 2 \\
& z_{j}^{\prime d}=z_{j}^{\prime}-\left(z_{j}-z_{j-1}^{\prime}\right) / 2, \quad j=1,2,3, \ldots, n-1 .
\end{aligned}
$$

The water vapor density of each atmospheric layer $\rho_{w}\left(z_{j}^{\prime}\right)$ was estimated using the equation from Hoffmann (Linke \& Baur 1970) for the calculation of the water vapor pressure $D\left(z_{j}^{\prime}\right)$. Then,

$$
\rho_{\mathrm{w}}\left(z_{\jmath}^{\prime}\right)=D\left(z_{\jmath}^{\prime}\right) /\left(R T\left(z_{j}^{\prime}\right)\right)
$$

where $R=$ specific gas constant, equal to $461.8 \mathrm{~J}$ $\mathrm{kg}^{-1} \mathrm{~K}^{-1}$.

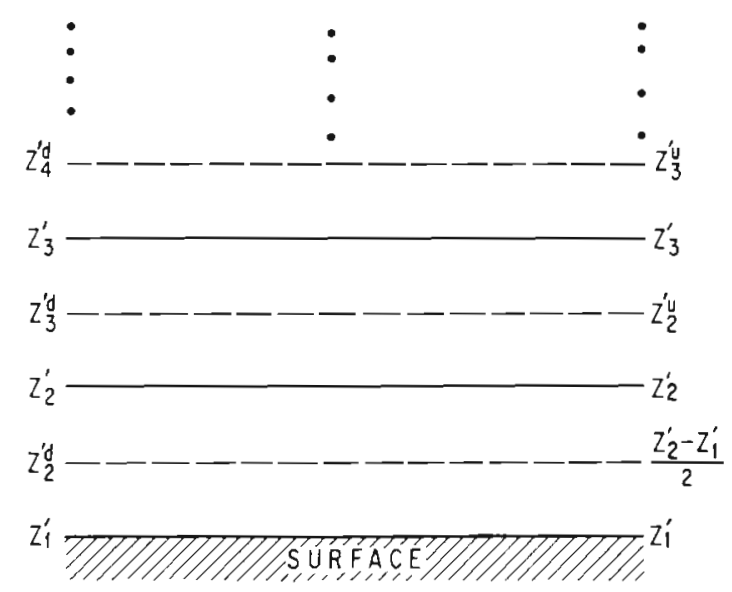

Fig. 1. Atmospheric paths for the calculation of Eq. (1) 
The carbon dioxide density was calculated assuming a constant mixing ratio of $350.6 \times 10^{-6}$ by volume in the atmosphere according to McClatchey et al. (1986). The ozone density distribution was taken from McClatchey et al. (1972) for midlatitude conditions (intermediate ozone values were interpolated)

The density and pressure distributions of the atmosphere are then combined with the effective mass absorption coefficients $\tilde{k}_{\lrcorner \lambda}$ to obtain the effective optical thickness values $\tilde{k}_{\lrcorner \lambda} m\left(z^{\prime}\right)$ for each wavelength band $\Delta \lambda$, for each absorbing gas and for each layer. The effect for all gases is given by the arithmetic sum of individual effective optical thicknesses. The temperature distribution for the atmosphere is used to compute the blackbody radiation for each wavelength band for each layer. The effective optical thickness and black-body radiation values for each wavelength band are then combined to evaluate the longwave net radiation at the surface for that band. Finally, the integration of Eq. (1) over all wavelength intervals $(M)$ gives the total longwave net radiation at the surface. Hence,

$$
L_{c} \cdots=\sum_{i=1}^{M}\left[(1-N) \int_{\lambda_{1}-\Delta \lambda_{1} / 2}^{\lambda_{1}+\Delta \lambda_{1} / 2}[\ldots] \mathrm{d} \lambda-N \int_{\lambda_{1}-\Delta \lambda_{1} / 2}^{\lambda_{1}+\Delta \lambda_{1} / 2}[\ldots] \mathrm{d} \lambda\right]
$$

\section{Radiation data acquisition}

For the comparison between calculated and measured values, the hourly radiation data $\left(\mathrm{J} \mathrm{cm}^{-2}\right)$ acquired at the Station Météorologique de CarpentrasSerres (France) for the year 1990 were used. This station is situated about $65 \mathrm{~km}$ from the Station de Radiosondage de Nimes-Courbessac, at an altitude of $99.3 \mathrm{~m}\left(44^{\circ} 05^{\prime} \mathrm{N}, 05^{\circ} 03^{\prime} \mathrm{E}\right)$. The measurements of longwave radiation were recorded through a pyrgeometer, measuring the net incident radiation on a horizontal upward-facing black surface, including both solar (shortwave) and atmospheric (longwave) radiation at ambient air temperature. Simultaneously, a pyranometer registered the solar radiation. Then, by subtraction of the solar component from the pyrgeometer data, it was possible to obtain measured values of the incident atmospheric radiation $L_{\mathrm{m}} \downarrow$. The 'measured' longwave net radiation at the surface, $L_{m}{ }^{*}$, was therefore computed as

$$
L_{\mathrm{m}} \cdots=\varepsilon \sigma T_{\mathrm{a}}^{4}-L_{\mathrm{m}} \downarrow
$$

where $\sigma=$ Stefan-Boltzmann constant. The surface emissivity $\varepsilon=0.984$ for a grass cover was chosen according to Möller (1973), and the air temperature $T_{a}$ used for the calculation of the black-body surface emission $\sigma T_{a}^{4}$ (because of lack of true surface temperature measurements $T_{\mathrm{s}}$ ).
The accuracy of $L_{m} \downarrow$ is of the order of $10 \%$ (due to the addition of measurement errors of near $5 \%$ ). The difference $T_{\mathrm{s}}-T_{\mathrm{a}}$ may increase to $10 \mathrm{~K}$ or more for daytime dry conditions and take negative values (up to 3 to $4 \mathrm{~K}$ ) at night. This results in a $10 \%$ error in the surface emission temperature. The expected accuracy of the measurements will, therefore, not improve beyond $\pm 20 \%$ (worldwide accepted value) when using the aforementioned procedure to obtain the $L_{\mathrm{m}} \cdots$ values.

\section{Radiosounding dates selection}

Many experimental studies have shown the great influence of geographical and orographical situation on the atmospheric conditions over a given place. Therefore, to compare the $L_{\mathrm{m}}$ "* values obtained from the radiation measurements of the Station CarpentrasSerres with those calculated using the radiosounding data of the Station Nimes-Courbessac (Eq. 1), it was necessary to select days when the sky showed nearly the same atmospheric behaviour over both stations. For this purpose, the surface measurements of the air temperature $T_{a}$, the relative humidity at the surface $R H_{0}$, the air pressure $p_{0}$ and the cloud cover degree $N$ of both stations were statistically compared.

Thus, 26 data sets corresponding to different 12:00 h UTC radiosounding dates in 1990 (Station NimesCourbessac) were selected for the calculation of Eq. (1) for the Region Nimes-Carpentras.

Although this procedure is not absolutely accurate, it is very probable that, at least for the selected radiosounding dates, the sky over both places showed approximately the same meteorological conditions.

\section{RESULTS AND DISCUSSION}

\section{Radiosounding data utilization}

Table 1 shows the measured and calculated hourly values of the longwave net radiation at the surface for the selected 26 radiosounding data sets.

The results of Table 1 and the regression analysis between calculated and measured values verify the good correlation between $L_{\mathrm{m}}{ }^{*}$ and $L_{c}{ }^{*}$ (correlation coefficient $r=0.9937$ ) for different sky conditions. The percentage differences between these variables (Fig. 2) always lie within the accuracy of the measurements.

These results also show that the highest percentage differences between $L_{\mathrm{m}}{ }^{*}$ and $L_{c}{ }^{*}$ appear, as expected, for broken cloud and overcast sky. According to Eq. (1) the precise knowledge of the height of the cloud base, $h_{0}$, is important for the accurate calculation 
Table 1 . Calculated values of the longwave net radiation at the surface, 12:00 h UTC, Region Nimes-Carpentras (France), hourly values $\left(\mathrm{J} \mathrm{cm}^{-2}\right) . N$ : fractional cloud cover index; $h_{\mathrm{o}}$ : height of cloud base $(\mathrm{m}) ; L_{\mathrm{m}} \downarrow$ : measured incident atmospheric radiation: $L_{m} \cdot$ : measured surface longwave net radiation; $L_{c}{ }^{\prime \prime}$ : calculated longwave net radiation; $L_{\mathrm{cc}}{ }^{\prime}$ : calculated longwave net radiation using Eq. (4); and $L_{\mathrm{p}}$ ": calculated longwave net radiation using Eq. (5) for the atmospheric transmission

\begin{tabular}{|c|c|c|c|c|c|c|c|}
\hline $\begin{array}{l}\text { Date } \\
\text { (1990) }\end{array}$ & $N$ & $h_{0}$ & $L_{m} \downarrow$ & $L_{\mathrm{m}} \cdot$ & $L_{c}{ }^{\prime \cdot}$ & $L_{c c}{ }{ }^{\prime}$ & $L_{p}{ }^{\prime \prime}$ \\
\hline 08 Jan & $0 / 8$ & & 90.0 & 36.9 & 36.9 & 44.9 & 36.2 \\
\hline $23 \mathrm{Jan}$ & $0 / 8$ & & 93.0 & 38.0 & 38.6 & 47.1 & 40.1 \\
\hline $01 \mathrm{Feb}$ & $8 / 8$ & 1500 & 122.0 & 8.2 & 8.7 & & 8.9 \\
\hline $02 \mathrm{Feb}$ & $4 / 8$ & 1200 & 128.0 & 8.0 & 8.2 & & 8.0 \\
\hline $22 \mathrm{Feb}$ & $0 / 8$ & & 107.0 & 37.4 & 36.6 & 42.7 & 36.2 \\
\hline $23 \mathrm{Feb}$ & $0 / 8$ & & 108.0 & 37.3 & 36.2 & 46.1 & 36.8 \\
\hline $04 \mathrm{Mar}$ & $0 / 8$ & & 91.0 & 43.3 & 43.7 & 52.3 & 43.9 \\
\hline $11 \mathrm{Mar}$ & $0 / 8$ & & 106.0 & 39.9 & 39.2 & 44.1 & 38.8 \\
\hline $12 \mathrm{Mar}$ & $8 / 8$ & 2300 & 123.0 & 12.6 & 11.2 & & 11.0 \\
\hline $16 \mathrm{Mar}$ & $0 / 8$ & & 112.0 & 39.0 & 40.7 & 45.4 & 41.3 \\
\hline $18 \mathrm{Mar}$ & $2 / 8$ & 1200 & 111.0 & 30.6 & 29.0 & & 28.7 \\
\hline $03 \mathrm{Apr}$ & $7 / 8$ & 1400 & 130.0 & 8.0 & 8.9 & & 7.1 \\
\hline $06 \mathrm{Apr}$ & $8 / 8$ & 700 & 125.0 & 2.7 & 2.3 & & 2.2 \\
\hline $07 \mathrm{Apr}$ & $5 / 8$ & 1700 & 129.0 & 11.4 & 10.0 & & 13.2 \\
\hline $14 \mathrm{Apr}$ & $3 / 8$ & 2000 & 114.0 & 20.0 & 21.1 & & 22.0 \\
\hline $20 \mathrm{Apr}$ & $7 / 8$ & 3400 & 116.0 & 16.9 & 16.0 & & 15.8 \\
\hline 03 May & $1 / 8$ & 1900 & 126.0 & 35.3 & 33.0 & & 33.9 \\
\hline $09 \mathrm{Jul}$ & $1 / 8$ & 1300 & 141.0 & 35.7 & 38.0 & & 38.4 \\
\hline $13 \mathrm{Jul}$ & $0 / 8$ & & 143.0 & 28.4 & 30.2 & 46.7 & 29.9 \\
\hline $19 \mathrm{Jul}$ & $1 / 8$ & 1300 & 145.0 & 26.7 & 23.2 & & 23.0 \\
\hline 20 Aug & $0 / 8$ & & 136.0 & 35.9 & 33.7 & 36.4 & 37.3 \\
\hline 23 Aug & $0 / 8$ & & 134.0 & 38.8 & 40.5 & 40.4 & 40.8 \\
\hline 24 Aug & $0 / 8$ & & 134.0 & 37.0 & 39.1 & 40.5 & 39.8 \\
\hline 02 Oct & $1 / 8$ & 3100 & 126.0 & 33.8 & 36.3 & 36.6 & 36.5 \\
\hline 15 Oct & $7 / 8$ & 1800 & 145.0 & 9.9 & 10.8 & & 11.0 \\
\hline 19 Oct & $8 / 8$ & 700 & 134.0 & 3.2 & 3.1 & & 2.9 \\
\hline
\end{tabular}

of the longwave net radiation at the surface, especially for dense and low-situated cloud layers $(N>2 / 8$ and $h_{0}<2500 \mathrm{~m}$ ). Consequently, it is probable that the observed $h_{0}$ values for Station Nîmes-Courbessac (used for the calculation of the $L_{c}{ }^{*}$ values) do not correspond exactly to the height of the clouds over Station Carpentras-Serres.

The results obtained through Eq. (1) were compared to the values calculated using empirical formulas. The equation of Choisnel (1988) for the south of France has been selected for the calculation of the longwave net radiation values for a clear atmosphere $L_{c c}$ “*

$$
L_{\mathrm{cc}} \cdots=\sigma T_{\mathrm{a}}^{4}\left[0.56-0.08, \overline{D_{\mathrm{o}}}\right]
$$

where $D_{0}=$ water vapor pressure at the surface derived from the relative humidity $R H_{0}$.

From the data shown in Table 1 and Figs. $2 \& 3$, and the correlation analysis between $L_{\mathrm{cc}}{ }^{*}$ and $L_{\mathrm{m}}{ }$. values $(r=0.3776)$, it is clear that the perfomance of Eq. (4) is by far poorer than the computation of the longwave net radiation from radiosounding data (Eq. 1). These results confirm the necessity of including the radiative contribution of the atmospheric layers above the surface in order to obtain a more accurate estimate of the longwave net radiation at the surface. Therefore, empirical equations based only on surface data represent a rough description of the hourly values of the longwave net radiation in the majority of cases.

This part of the present study also corroborates the results obtained by Gonima $(1988 a$, b) for Central Europe.

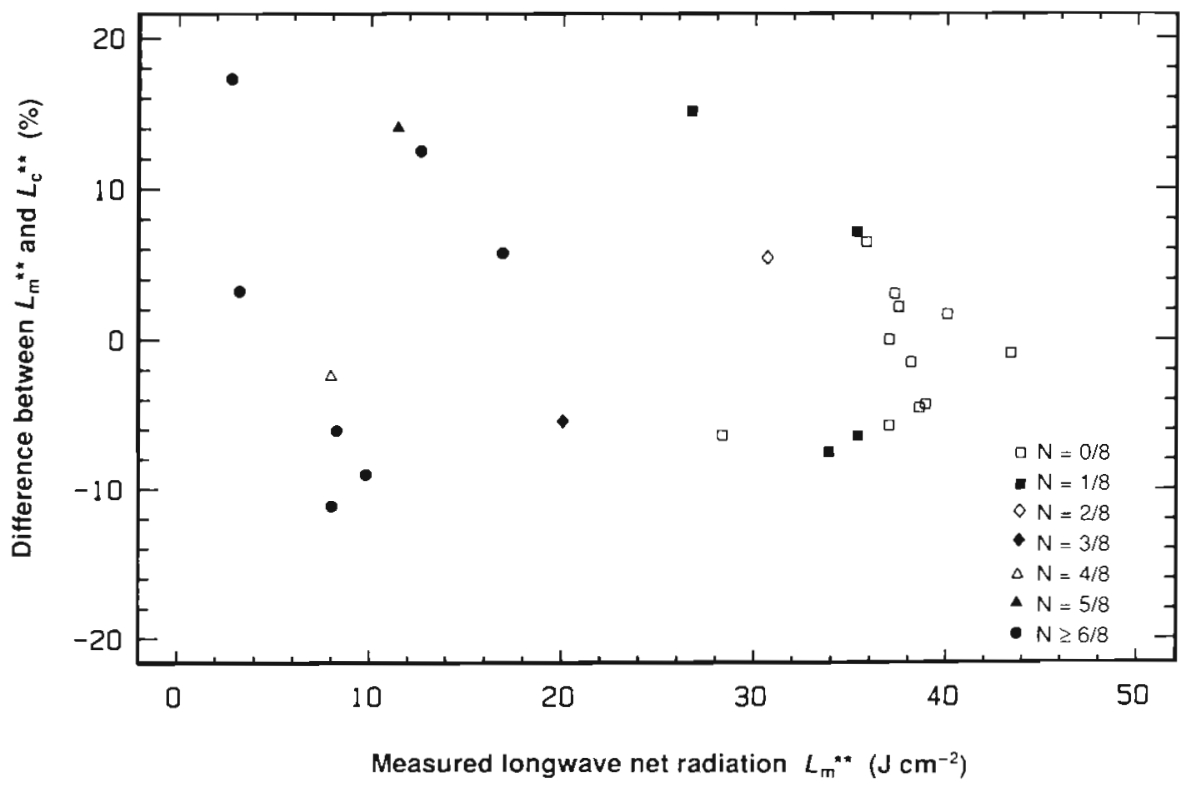

Fig. 2. Percentage difference between measured $L_{\mathrm{m}} "$ " and calculated $L_{c}{ }^{\cdots}$ hourly values. Region Nîmes-Carpentras (France) 
Fig. 3. Percentage difference between measured $L_{\mathrm{m}}{ }^{\prime \prime}$ and calculated $L_{c c} "$ hourly values, clear sky. Region Nimes-Carpentras (France)

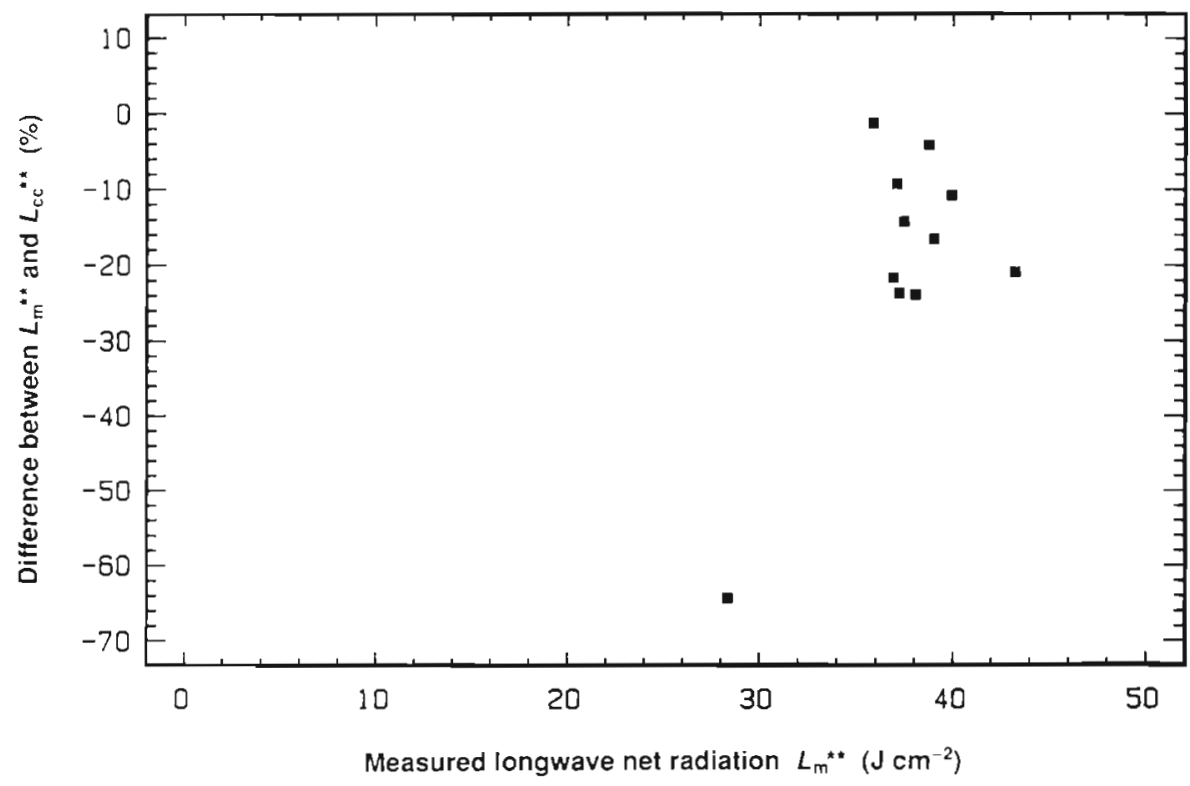

\section{Simplified transmission function utilization}

The following expression (Kondratyev 1965) for the transmission function was used for the simplified calculation of the longwave net radiation at the surface, $L_{\mathrm{p}} \cdot \cdots$ :

$$
P_{\lambda}\left(m\left(z^{\prime}\right)\right) \approx \exp \left[-1.66 \tilde{k}_{\Delta \lambda} m\left(z^{\prime}\right)\right]
$$

Table 1 shows the good agreement between the calculated values of the longwave net radiation $L_{\mathrm{p}}{ }{ }^{\prime}$, and the measured $\left(L_{\mathrm{m}}{ }{ }^{\prime}\right)$ values. Therefore, the use of the simplified transmission function could also give useful results for the calculated longwave net radiation at the surface.

\section{Calculation of longwave net radiation for model atmospheres}

This section represents an attempt to simplify the calculation of the longwave net radiation at the surface using empirical expressions for the atmospheric profiles. Note that the applicability of the following empirical equations is restricted to the study area, due to regional variations of these parameters.

Since calculation of the $L_{c}{ }^{*}$ values using the radiosounding data of Station Nimes-Courbessac showed that the influence of the $\mathrm{CO}_{2}$ and $\mathrm{O}_{3}$ absorption is practically negligible, Eq. (1) has been simplified so that only the water vapor absorption is taken into account.

The following equations (derived from the correlative analysis of the radiosounding data for 1990 ,
Station Nîmes-Courbessac) are proposed for the calculation of the temperature $T\left(z^{\prime}\right)$, water vapor density $\rho_{\mathrm{w}}\left(z^{\prime}\right)$ and pressure $p\left(z^{\prime}\right)$ for 3 different types of sky conditions:

(1) For a clear $(N=0 / 8)$ and broken cloud atmosphere $(0 / 8<N<7 / 8)$ the expressions suggested by Bliss (1961) are recommended:

$$
T\left(z^{\prime}\right)=T_{\mathrm{a}}+\gamma z^{\prime}
$$

where $\gamma=-0.0065 \mathrm{~K} \mathrm{~m}^{-1}$ and $z^{\prime}$ is given in meters

$$
\rho_{\mathrm{w}}\left(z^{\prime}\right)=\rho_{\mathrm{w}}(0) \exp \left(-\alpha z^{\prime}\right)
$$

where $\rho_{w^{\prime}}(0)$ represents the water vapor density at surface level calculated from the relative humidity $R H_{\circ}$ (Eq. $2 c$ for $z^{\prime}=0$ ). The value of the constant $\alpha$ is assumed to be $0.0004 \mathrm{~m}^{-1}$ to fit midlatitude weather.

$$
p\left(z^{\prime}\right)=p_{0} \exp \left(-\beta z^{\prime}\right)
$$

where $p_{0}=$ air pressure, and the constant $\beta=$ $0.00012 \mathrm{~m}^{-1}$.

(2) For a clear atmosphere with temperature inversion within the first $1000 \mathrm{~m}$ of height, the atmosphere was divided into 2 parts:

(a) Atmospheric layers between 0 and $1000 \mathrm{~m}$ over the surface (temperature inversion),

$$
\begin{aligned}
& T\left(z^{\prime}\right)=T_{\mathrm{a}}+0.015 z^{\prime} \\
& \rho_{\mathrm{w}}\left(z^{\prime}\right)=\rho_{w}(0) \\
& p\left(z^{\prime}\right)=p_{0} \exp \left(-0.00012 z^{\prime}\right)
\end{aligned}
$$


(b) Atmospheric layers above $1000 \mathrm{~m}$ (no temperature inversion): Eqs. (6), (7) \& (8) are recommended for this part of the calculations.

(3) For an overcast atmosphere $(N>6 / 8)$ :

$$
T\left(z^{\prime}\right)=T_{a}-0.009 z^{\prime}
$$

The water vapor distribution $\rho_{w}\left(z^{\prime}\right)$ and the atmospheric pressure $p\left(z^{\prime}\right)$ can be calculated using Eqs. (7) \& (8) respectively.

To calculate the longwave net radiation at the surface using the proposed empirical relationships, $L_{\mathrm{cm}}{ }{ }^{\circ}$, the atmosphere was divided into 51 equally spaced layers, each $100 \mathrm{~m}$ in thickness. Then, using the surface measurements of $T_{a}, R H_{0}, p_{0}$ and the cloud cover index $N$ as input data, 199 hourly $L_{\mathrm{cm}}$ " values were calculated for Station Carpentras-Serres.

Fig. 4 shows some examples of the results for $L_{\mathrm{cm}}$ " obtained using the empirical models for the calculation of the atmospheric profiles.

Although the uncertainty in the $L_{\mathrm{cm}}$ " values is greater than that in the $L_{c}$ "* values (calculated through Eq. 1), the results obtained in this part of the work are more accurate than those calculated using Eq. (4) for a clear atmosphere (Fig. 5).

Close examination of Table 2, extracted from the results shown in Fig. 4, reveals that the suggested expressions for the calculation of the atmospheric profiles for the case of an atmosphere with temperature inversion represent a relatively good approximation for the estimation of the actual $L_{\mathrm{m}}$ " values. However, its applicability is limited due to the impossibility of identifying the start of a temperature inversion process from meteorological surface measurements. The failure to consider this process in the calculations results in overestimation of the calculated longwave net radiation at the surface.

Nevertheless, calculation of the longwave net radiation for an atmosphere with temperature inversion, using Eq. (6) for the temperature profile, could give even better results than those calculated by Eq. (4).

\section{Sensitivity test discussion}

In a sensitivity study (Wendisch \& Gonima 1988) of the present radiation model for a clear and broken cloud atmosphere, the authors showed that the water vapor distribution in the atmosphere has the largest influence on the estimation of the longwave net radiation at the surface, whilst variations of the temperature and pressure profiles have an insignificant effect. For an overcast sky, the longwave net radiation depends mainly on the vertical position of the cloud base (this being the consequence of the assumption that the cloud base acts as a blackbody).

On the other hand, variations of the air temperature $T_{a}$, relative humidity $R H_{0}$ and pressure $p_{0}$ have a negligible effect on the calculation of the longwave net radiation at the surface. These results corroborate the great limitation of the empirical equations (based only on surface parameters) for representing the longwave net radiation at the surface with the required accuracy.

\section{CONCLUSIONS}

The present study confirms that precise determination of the longwave net radiation at the surface relies strongly on the vertical distribution of the

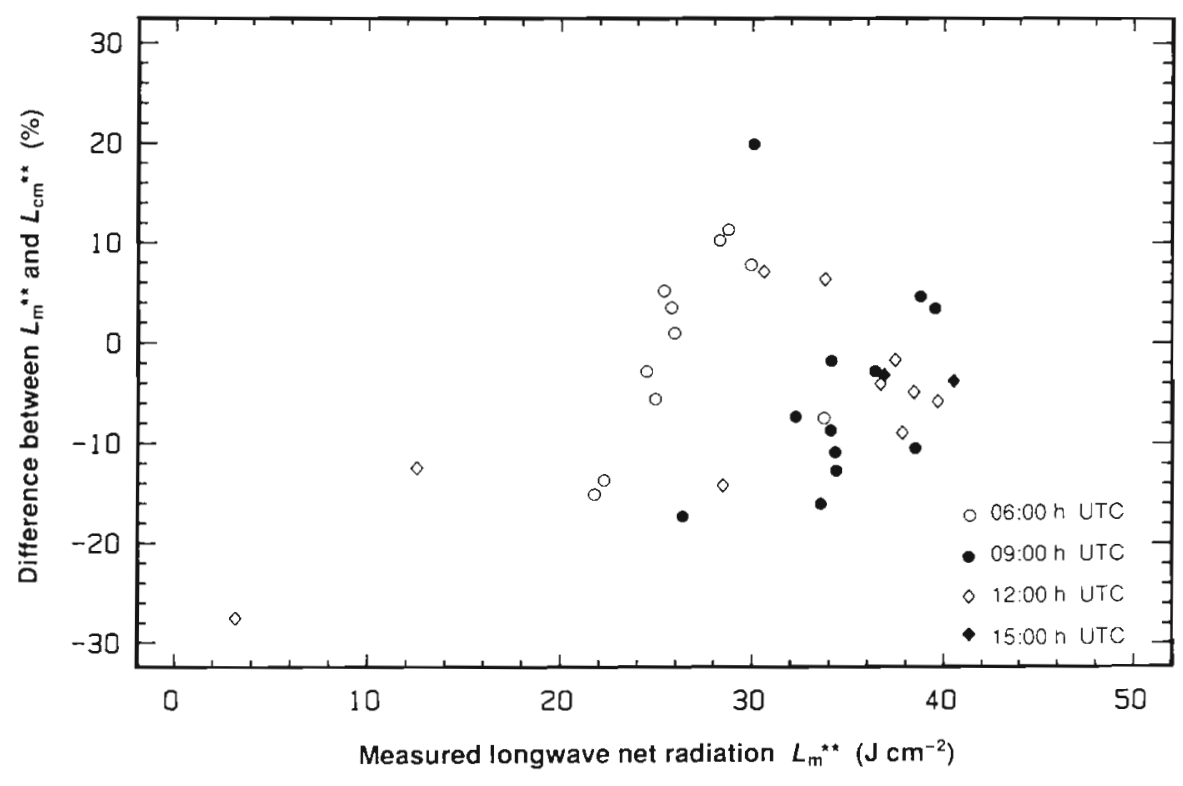

Fig. 4. Percentage difference (examples) between measured $L_{\text {in }}$ " and calculated $L_{\mathrm{cm}}$ " hourly values, Station Carpentras-Serres (France). Values of $h_{0}$ (cloud base height) are taken from the 12:00 h UTC radiosounding data of the Station Nimes-Courbessac (France) 
Fig. 5. Percentage differences (examples) between measured $L_{m}$. and calculated $L_{c c}$ ". hourly values, clear sky. Station Carpentras-Serres (France)

atmospheric constituents, i.e. the calculation requires the introduction of the radiative contribution of the atmospheric layers above the surface in order to obtain accurate results. Empirical relationships based only on surface measurements of the air temperature, the relative humidity or the partial water vapor pressure cannot represent the actual longwave radiation regime with sufficient accuracy in most cases.

The new validation of Eq. (1) presented in this work verifies its spatial and temporal applicability: the calculated longwave net radiation data always lie within the accuracy of the measurements. Therefore, it seems possible to apply the proposed radiation model to any region of the world and also to couple it with

Table 2. Examples of calculation of the longwave net radiation at the surface for an atmosphere with temperature inversion (clear sky), hourly values $\left(\mathrm{J} \mathrm{cm}^{-2}\right)$. (1) Measured $L_{\mathrm{m}}$ " values; (2) calculated longwave net radiation using the proposed empirical equations for the temperature inversion;(3) calculated longwave net radiation without inclusion of temperature inversion; and (4) longwave net radiation $L_{\mathrm{cr}}$. calculated by Eq. (4)

\begin{tabular}{|lccccc|}
\hline $\begin{array}{l}\text { Date } \\
\text { (1990) }\end{array}$ & $\begin{array}{c}\text { Time (h) } \\
\text { (UTC) }\end{array}$ & (1) & (2) & (3) & (4) \\
\hline 21 Jan & $09: 00$ & 27.8 & 28.6 & 36.7 & 45.5 \\
12 Jul & $06: 00$ & 28.7 & 26.8 & 36.6 & 40.1 \\
12 Jul & $09: 00$ & 27.2 & 29.6 & 40.3 & 42.6 \\
13 Jul & $06: 00$ & 29.8 & 27.8 & 37.8 & 41.1 \\
13 Jul & $09: 00$ & 26.4 & 31.0 & 42.0 & 44.5 \\
18 Jul & $06: 00$ & 29.3 & 25.1 & 35.6 & 34.2 \\
20 Jul & $06: 00$ & 27.4 & 25.8 & 35.8 & 37.1 \\
26 Jul & $06: 00$ & 27.5 & 26.4 & 36.6 & 37.4 \\
08 Aug & $06: 00$ & 26.9 & 27.1 & 36.8 & 41.0 \\
09 Aug & $06: 00$ & 26.8 & 26.3 & 35.9 & 40.0 \\
\hline
\end{tabular}

global or local climate models in order to improve understanding of the influence of variations in longwave radiation on the climatic conditions of a given region or place.

Furthermore, the proposed empirical expressions for the calculation of atmospheric profiles simplify estimation of the longwave net radiation. Although their utilization does not require any previous knowledge about the structure and composition of the atmosphere, applicability is restricted to the region of study. The accuracy of the results could also be sufficient for many agrometeorological applications such as energy and radiation balance calculations, and evapotranspiration estimations.

The analytical effort consists of a simple numerical technique for calculating the longwave net radiation at the surface using atmospheric profiles derived from radiosounding measurements and/or from local climatological parametrizations.

Finally, adequate comprehension and description of the temperature inversion process in the future will improve the estimation of the longwave net radiation at the surface.

Acknowledgements. This study was perfomed during a postdoctoral fellowship at the Station de Bioclimatologie-INRA Montfavet (France). The author thanks Dr Alain Baille, director of the laboratory, and Dr André Juhel, in charge of the Climatological Service (STEFCE-INRA), for their great interest and invaluable collaboration during the completion of this work. This gratitude is extended to the Stations de Carpentras-Serres and Nîmes-Courbessac (Météo France) for the supply and compilation of the measured data. The invaluable scientific comments of Dr Bernard Seguin of the Station de Bioclimatologie-INRA (Montfavet-France) are especially acknowledged. 
Appendix 1. Calculated mass absorption coefficients

\begin{tabular}{|c|c|c|c|c|c|}
\hline$\lambda(\mu \mathrm{m})$ & $\bar{k}_{د \lambda}\left(\mathrm{m}^{2} \mathrm{~kg}^{-1}\right)$ & $\Delta \lambda(\mu \mathrm{m})$ & $\lambda(\mu \mathrm{m})$ & $\tilde{k}_{\Delta \lambda}\left(\mathrm{m}^{2} \mathrm{~kg}^{-1}\right)$ & $\Delta \lambda(\mu \mathrm{m})$ \\
\hline \multirow{2}{*}{ Water vapor } & & & 25.45 & 2.62 & 1.12 \\
\hline & & & 26.28 & 0.50 & 0.52 \\
\hline 5.25 & 4.0 & 0.5 & 26.79 & 0.78 & 0.52 \\
\hline 6.25 & 17.35 & 1.5 & 27.18 & 2.62 & 0.27 \\
\hline 7.08 & 0.815 & 0.16 & 27.52 & 0.30 & 0.40 \\
\hline 7.22 & 0.525 & 0.13 & 27.86 & 2.62 & 0.28 \\
\hline 7.36 & 0.310 & 0.15 & 29.00 & 11.80 & 2.00 \\
\hline 7.67 & 0.470 & 0.47 & 32.00 & 16.05 & 4.00 \\
\hline 7.95 & 0.086 & 0.10 & 34.50 & 9.00 & 1.00 \\
\hline 8.08 & 0.014 & 0.16 & 36.50 & 20.00 & 3.00 \\
\hline 8.22 & 0.011 & 0.13 & 38.05 & 0.90 & 0.10 \\
\hline 8.46 & 0.014 & 0.35 & 38.20 & 0.48 & 0.19 \\
\hline 9.63 & 0.006 & 2.00 & 38.48 & 0.31 & 0.38 \\
\hline 11.13 & 0.005 & 1.00 & 38.86 & 0.56 & 0.38 \\
\hline 11.95 & 0.016 & 0.65 & 39.15 & 1.10 & 0.20 \\
\hline 12.37 & 0.029 & 0.18 & 40.23 & 20.00 & 1.95 \\
\hline 12.75 & 0.061 & 0.57 & 41.31 & 1.10 & 0.20 \\
\hline 13.13 & 0.083 & 0.20 & 41.51 & 0.62 & 0.20 \\
\hline 17.21 & 0.338 & 1.08 & 41.72 & 0.32 & 0.21 \\
\hline 17.80 & 0.16 & 0.09 & 42.00 & 0.10 & 0.41 \\
\hline 17.93 & 0.10 & 0.17 & 42.34 & 0.16 & 0.21 \\
\hline 18.06 & 0.148 & 0.09 & 42.54 & 0.52 & 0.21 \\
\hline 18.29 & 0.32 & 0.36 & 42.83 & 0.90 & 0.35 \\
\hline 18.56 & 0.152 & 0.18 & 71.64 & 20.00 & 56.72 \\
\hline 18.79 & 0.10 & 0.28 & & & \\
\hline 19.02 & 0.17 & 0.18 & Carbon dioxide & & \\
\hline 19.59 & 0.36 & 0.96 & & & \\
\hline 20.17 & 0.24 & 0.20 & 13.39 & 0.17 & 0.31 \\
\hline 20.37 & 0.156 & 0.20 & 13.77 & 0.82 & 0.45 \\
\hline 20.62 & 0.25 & 0.30 & 15.00 & 20.00 & 2.00 \\
\hline 20.92 & 0.165 & 0.30 & 16.33 & 0.88 & 0.66 \\
\hline 21.44 & 0.635 & 0.73 & & & \\
\hline 22.00 & 1.27 & 0.40 & Ozone & & \\
\hline 22.30 & 0.30 & 0.20 & & & \\
\hline 22.70 & 0.66 & 0.60 & 9.17 & 34.00 & 0.19 \\
\hline 23.30 & 0.31 & 0.60 & 9.29 & 130.00 & 0.06 \\
\hline 23.83 & 2.62 & 0.46 & 9.36 & 272.00 & 0.08 \\
\hline 24.11 & 0.77 & 0.11 & 9.44 & 406.00 & 0.08 \\
\hline 24.23 & 0.20 & 0.12 & 9.54 & 395.00 & 0.13 \\
\hline 24.35 & 0.10 & 0.12 & 9.68 & 333.00 & 0.13 \\
\hline 24.47 & 0.05 & 0.12 & 9.80 & 216.00 & 0.12 \\
\hline 24.59 & 0.11 & 0.12 & 9.90 & 112.00 & 0.09 \\
\hline 24.71 & 0.216 & 0.12 & 10.00 & 40.00 & 0.09 \\
\hline 24.83 & 0.29 & 0.12 & 10.09 & 7.50 & 0.09 \\
\hline
\end{tabular}

\section{LITERATURE CITED}

Ångström, A. (1929). Über Variationen der atmosphärischen Temperaturstrahlung und ihren Zusammenhang mit der Zusammensetzung der Atmosphäre. Gerlands Beitr. Geophys. 21. 145-161

Bliss, R. W. Jr (1961). Atmospheric radiation near the surface of the ground: a summary for engineers. Solar Energy 5: $103-120$

Brunt, D. (1932). Notes on radiation in the atmosphere. Q. J. R. meteorol. Soc. 58: $389-418$

Brutsaert, W. (1975). On a derivable formula for longwave radiation from clear skies. Water Resour. Res. 11: $742-744$
Choisnel, E. (1988). Estimation de l'évapotranspiration potentielle à partir des données météorologiques. La Météor. 23: 19-27

Gonima, L. (1988a). Die Berechnung der' effektiven Ausstrahlung am Erdboden aus klimatologischen Daten. Z. Meteorol. 38 (1):26-30

Gonima, L. (1988b). Eine Untersuchung über die langwellige Strahlungsbilanz am Erdboden unter verschiedenen Bedingungen. Z. Meteorol. 38 (3): 136-144

Idso, S. B. (1974). On the use of equations to estimate atmospheric thermal radiation. Arch. Meteor. Geophys. Bioklimatol. 22 (B): 287-299

Kondratyev, K. Ya. (1965). Radiative heat exchange in the atmosphere. Pergamon Press, Cambridge 
Linke, F., Baur, F. (1970). Meteorologisches Taschenbuch. Akademische Verlagsgesellschaft Geest \& Portig K.-G., Leipzig

McClatchey, R. A., Fenn, R. W., Selby, J. E. A., Volz, F. E., Garing, J. S. (1972). Optical properties of the atmosphere. A.ir Force Cambridge Res. Labs., AFCRL-72-0497

McClatchey, R. A., Bolle, H.-J., Kondratyev, K. Ya. (1986). A preliminary cloudless standard atmosphere for radiation computation. World Meteorological Organization (WMO),

Editor: G. Esser
World Climate Research Programme (WCRP). WMO/TDNo. 24, WCP-112, Geneva

Moller, F. (1973). Einführung in die Meteorologie II. Bibliographisches Institut, Mannheim

Swinbank, W. C. (1963). Long wave radiation from clear skies. Q. J. R. meteorol. Soc. 89: 339-348

Wendisch, M., Gonima, L. (1988). Nonlinear sensitivity analysis of a radiation model. Z. Meteorol. 38(5): $328-331$

Manuscript first received: August 12, 1991

Revised version accepted: January 2, 1992 